\title{
Human Umbilical Cord Mesenchymal Stem Cells Over Platelet Rich Fibrin Scaffold for Mandibular Cartilage Defects Regenerative Medicine
}

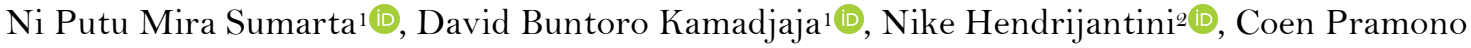 \\ Danudiningrat ${ }^{1}\left(\mathbb{D}\right.$, Fedik Abdul Rantam ${ }^{3}$ (1)
}

\begin{abstract}
'Department of Oral and Maxillofacial Surgery, Faculty of Dental Medicine, Universitas Airlangga, Surabaya, Indonesia.
${ }^{2}$ Department of Prosthodontics, Faculty of Dental Medicine, Universitas Airlangga, Surabaya, Indonesia.

${ }^{3}$ Department of Microbiology, Faculty of Veterinary Medicine, Universitas Airlangga, Surabaya, Indonesia.
\end{abstract}

Correspondence: Ni Putu Mira Sumarta, DMD., Ph.D., OMFS, Universitas Airlangga, Jl. Prof. Dr. Moestopo 47, Surabaya, Indonesia.60132. E-mail:niputu.mira@fkg.unair.ac.id

Academic Editor: Alessandro Leite Cavalcanti

Received: 01 March 2020 / Review: 18 May 2020 / Accepted: 11 July 2020

\begin{abstract}
How to cite this article: Sumarta NPM, Kamadjaja DB, Hendrijantini N, Danudiningrat CP, Rantam FA. Human umbilical cord mesenchymal stem cells over platelet rich fibrin scaffold for mandibular cartilage defects regenerative medicine. Pesqui Bras Odontopediatria Clín Integr. 2021; 21 :e0034. https://doi.org/10.1590/pboci.2021.020
\end{abstract}

\begin{abstract}
Objective: To evaluate the regeneration of mandibular cartilage defect after implantation of human umbilical cord mesenchymal stem cells (hUCMSC) over platelet rich fibrin (PRF) as scaffold. Material and Methods: 20 male Wistar rats were randomly divided into four experimental groups consisting of: a control group featuring untreated mandibular defects (C), experimental groups whose mandibular defects were implanted with hUCMSC (E1), mandibular defects implanted with PRF (E2), mandibular defects implanted with hUCMSC and PRF scaffold (E3). The subjects were sacrificed after six weeks of observation for immunohistochemical examination in order to evaluate the expression of Ki67, Sox9, FGF 18, type 2 collagen, and aggrecan, in addition to histology examination to evaluate chondrocyte number and cartilage thickness. Data was analyzed with univariate analysis (ANOVA). Results: The implantation of hUCMSC and PRF scaffold proved capable of regenerating mandibular cartilage defect through the expression of FGF 18, Sox9, Ki67, chondrosis counts, type 2 collagen, aggrecan, and cartilage thickness. The regeneration were significantly higher in group E3. Conclusion: Human umbilical cord mesenchymal stem cells in platelet rich fibrin scaffold proved capable of regenerating mandibular cartilage defect.
\end{abstract}

Keywords: Mesenchymal Stem Cells; Cord Blood Stem Cell Transplantation; Cartilage. 


\section{Introduction}

Mandibular cartilage defect can be caused by micro and macro trauma [1] resulting in debilitating effects such as prolonged pain, function impairment, chronic inflammation and progressive cartilage degeneration [2]. In fact, mandibular cartilage defect in children may impair mandibular growth [3]. Posttrauma cartilage degeneration occurs because of low regenerative capacity due to the avascular, alimphatic and aneural nature of articular cartilage and chondrocyte in a low turn-over to maintain extracellular matrix [4].

Various methods that had been developed in orthopedics to reconstruct cartilage defects such as subchondral drilling, abrasion, microfracture, mosaicplasty, autologous chondrocyte implantation and matrixassisted autologous chondrocyte implantation, have not yet been proven capable of providing a long and wellfunctioning cartilage in an extensive defect [5]. Autologous chondrocyte injection initiated in 1994 by Brittberg et al. [6] suffered from several disadvantages: limited cell procurement, donor site morbidity and limited potential for proliferation and differentiation [7]. In Oral and Maxillofacial Surgery, reconstruction of cartilage defect using autograft, allograft, and allopalstic material pose several disantantages and complication such as injury to facial nerve and temporomandibular nerve, and Frey's syndrome [1].

Cartilage generation requires a sufficient number of cells to replace damaged chondrocytes. Mesenchymal stem cells (MSCs) were considered a potential source in cartilage regeneration and engineering because of their high expansion rate [8]. The umbilical cord is a potential source of MSCs with several advantages such as being procured ethically from biological waste and demonstrating a high expansion rate $[9]$.

Stem cell implantation requires scaffold for cell growth and development. Platelet rich fibrin (PRF) is a natural fibrin matrix polymer, attracting fibroblast and undifferentiated cells into the matrix. PRF also contains growth factors such as PDGF- $\beta$, TGF $\beta-1$, VEGF, IGF-I, IL-1 $\beta$, IL-6, IL-4 and TNF- $\alpha$ [10]. However, regeneration of mandibular cartilage defects through the implantation of hUCMSC over PRF scaffold remains to be studied.

This study was performed to evaluate regeneration of surgically created mandibular cartilage defects in rat subjects after implantation of hUCMSC over PRF scaffold through expression of FGF 18, Sox9, Ki67, chondrocyte counts, type 2 collagen, aggrecan, and cartilage thickness. FGF 18 regulates chondrocyte proliferation, produces ECM and proteoglican. It attaches to FGFR-3 that cause anabolic effect in cartilage formation [11].

\section{Material and Methods}

Preparation of Experimental Subjects

This study was conducted following the granting of Ethical Clearance by the Animal Care and Use Committee, Faculty of Veterinary Medicine, Universtas Airlangga, Indonesia; number 430-KE, 14 April 2015 and constituted a true experimental post-test only control group study. Twenty male, albinus strain Rattus novergicus aged three months and 200-300 grams in weight were used as animal subjects. These were randomly divided into four experimental groups, consisting of: (C) a control group with untreated mandibular defects, (E1) experiment groups had mandibular defects implanted with hUCMSC, (E2) mandibular defects implanted with PRF (E3) mandibular defects implanted with hUCMSC and PRF scaffold.

Human Umbilical Cord Mesenchymal Stem Cell Isolation and Expansion Culture

An umbilical cord was obtained from a healthy C-section birth at Dr. Soetomo Public Hospital, Surabaya, Indonesia. Isolation and expansion culture were conducted according to the protocols of the Stem 
Cell Research and Development Center, Institute of Tropical Disease, Universitas Airlangga, Indonesia. Characterisation of MSC was conducted prior to implantation by means of immunocytochemical and flowcytometric analysis [12].

Preparation of PRF

After an animal subject had been anaesthetized with Ketamin/Xylazin, $1.5 \mathrm{ml}$ of venous blood were aspirated from its tail. The blood was obtained using a $3 \mathrm{ml}$ disposable syringe without anticoagulant and centrifuged at 3,000 rpm for ten minutes until it separated into three layers, the middle layer being PRF.

\section{Implantation of hUCMSC, PRF and hUCMSC and PRF}

Mandibular cartilage defects were created surgically in the anterior portion of the condylar superior surface using a round bur $1 \mathrm{~mm}$ in diameter [13]. Two million $\left(2 \times 10^{6}\right)$ hUCMSC pellets were implanted in group E1, 1 mm of PRF was implanted in group E2, while group E3 was implanted with hUCMSC seeded in 1 mm PRF through centrifugation at 3,000 rpm for five minutes. After the defects had been fully covered, the wound was sutured in layers.

Specimens Preparation and Microscopic Examination

The subjects were sacrificed after a 6-week period of observation. The mandible was subsequently exarticulated and fixated with $20 \%$ formalin for two days at room temperature and decalcified in $10 \%$ Ethylenediaminee tetra-acetic (EDTA) for eight weeks before being embedded in paraffin. Each paraffin block was cut axially to a thickness of $4 \mu \mathrm{m}$, deparaffinized and dehydrated. Specimens were then stained with Harris Hematoxylin-Eosin to enable histological examination to be conducted in order to evaluate chondrocyte counts and cartilage thickness. Immunohistochemical examination was undertaken to evaluate expression of FGF 18 using polyclonal anti FGF18 (PAC907Mu01) antibodies, Cloud-Clone Corp, USA), expression of Sox9 using polyclonal anti Sox9 (sc-20095) antibodies, Santa Cruz Biotechnology, Inc, USA), expression of Ki67 using polyclonal anti Ki67 (sc-15402) antibodies, Santa Cruz Biotechnology, Inc, USA), expression of type 2 collagen using polyclonal anti Coll2 antibodies (sc-7763, Santa Cruz Biotechnology, Inc, USA) and expression of aggrecan using polyclonal anti aggrecan antibodies (GTX54920, GeneTex, USA). Cell number were average number of cells counted manually in 20 visual field under light microscope.

Statistical Analysis

Data analyzed with univariate analysis (ANOVA) using SPSS software version 21.0 (IBM SPSS, Inc, Chicago, IL, USA) at $\mathrm{P}<0.05$ was considered statistically significant.

\section{Ethical Clearance}

This study received ethical approval from the Ethical Committee Dr. Soetomo General Hospital Surabaya, Indonesia (Number 379/Panke.KKE/VII/2015).

\section{Results}

Isolation and Culture of Human Umbilical Cord Mesenchymal Stem Cells

hUCMSC previously isolated and cultured displayed the character of MSC that expressed surface markers such as $\mathrm{CD} 45^{-}, \mathrm{CD} 73^{+}, \mathrm{CD}^{+} 0^{+}, \mathrm{CD} 105^{+}$. 
Expression of Ki67, FGF 18, Sox9 and chondrocyte numbers

The proliferation of hUCMSC and its differentiation into chondrocyte were evidenced by the expression of Ki67, FGF18, Sox9 and chondrocyte numbers. Microscopic images of cells expressing Ki67, FGF 18, Sox9, and chondrocyte counts are contained in Figure 1. Mean and deviation standard values for each proliferation and differentiation variable are presented in Figure 2.
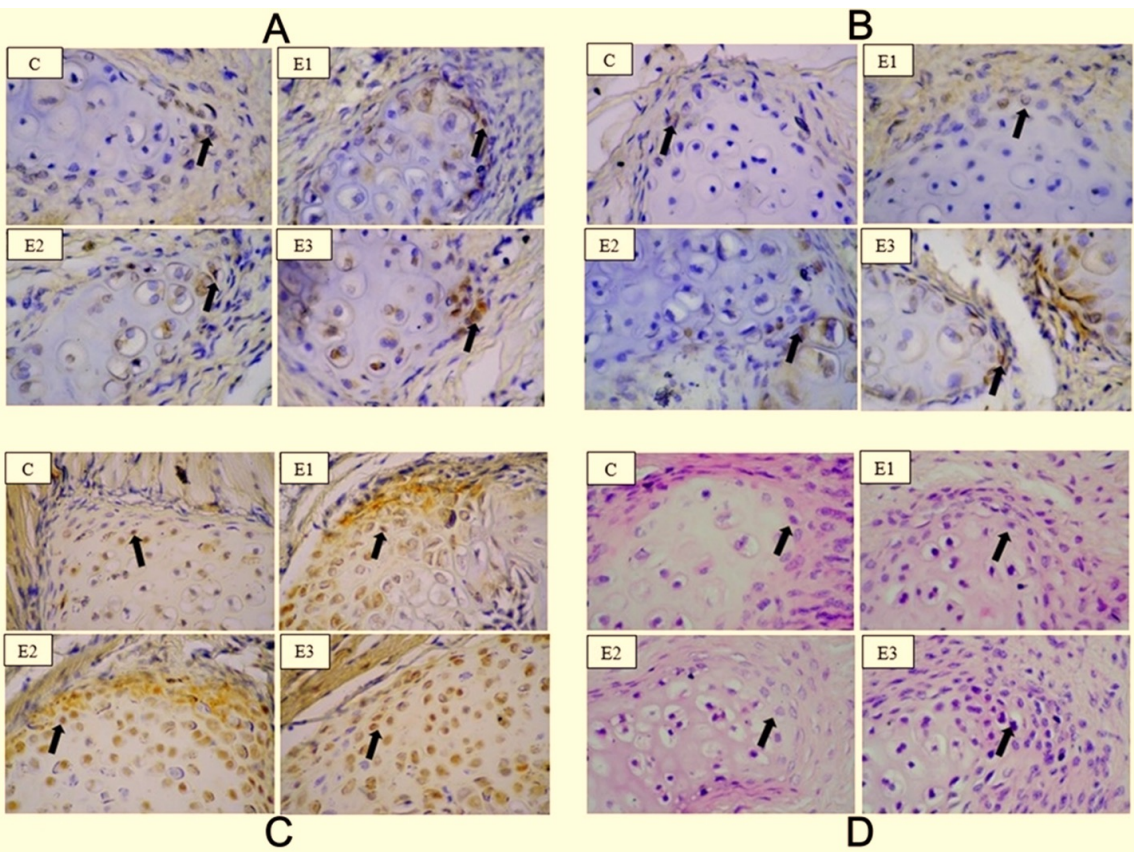

Figure 1. Microscopic image of immunohistochemical staining of cells expressing ki67 (A), FGF18 (B), Sox9 (C), and HE staining of chondrocyte counts (D). Examination was carried out under light microscope, at 400x magnification. Black arrows show cells expressing Ki67, FGF 18, Sox9 and Chondrocyte.

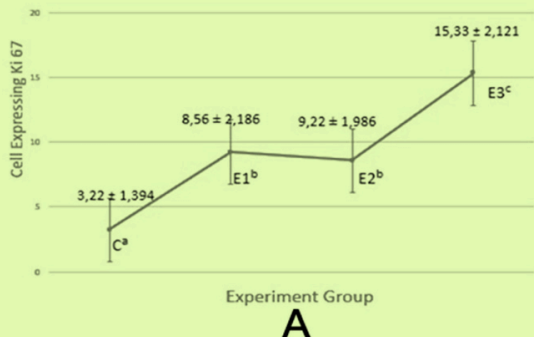

A

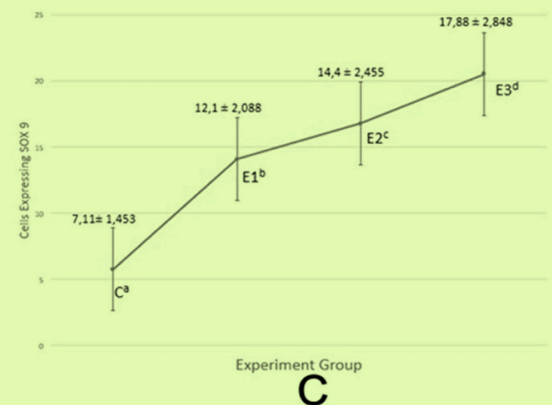

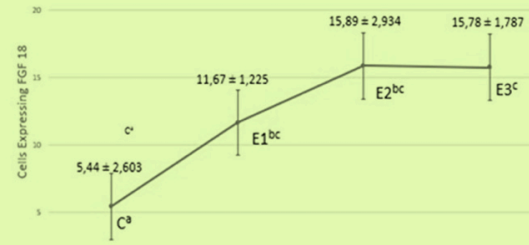

B

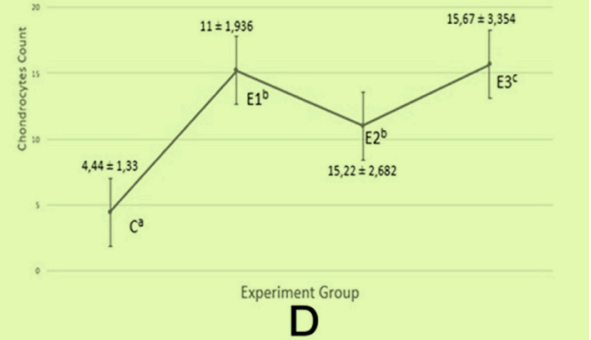

Figure 2. Graph of mean value and deviation standard of each group, expression of Ki67 (A), expression of FGF 18 (B), expression of Sox9 (C), Chondrocyte counts (D). Different superscript shows the statistical difference between groups $(\mathbf{p}<0.05)$. 
Expression of Type 2 Collagen, Aggrecan and Cartilage Thickness

Matrix deposition was represented by the expression of type 2 collagen and aggrecan, whereas the regeneration of cartilage was evidenced by cartilage thickness. Microscopic images of cells expressing type 2 collagen and aggrecan, as well as cartilage thickness; the mean and deviation standard values of each matrix deposition and regeneration variable are presented in Figure 3.

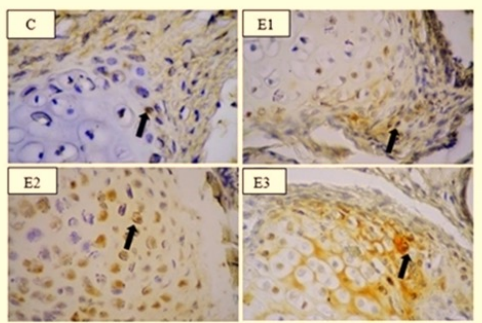

A

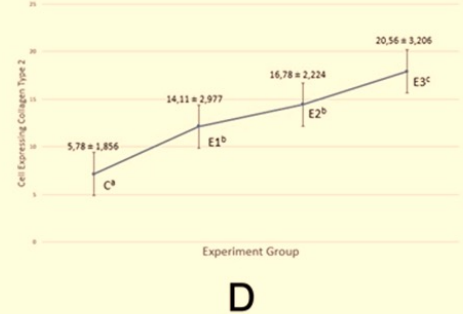

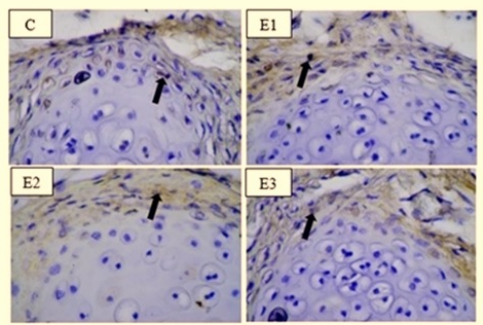

B

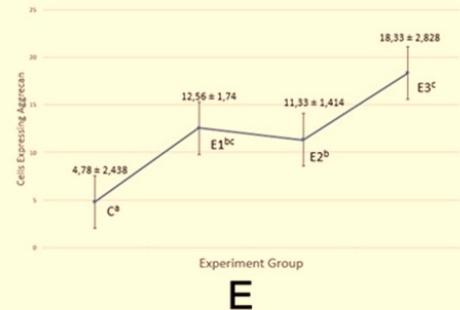

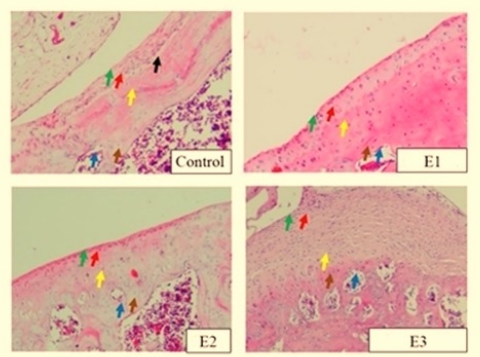

C

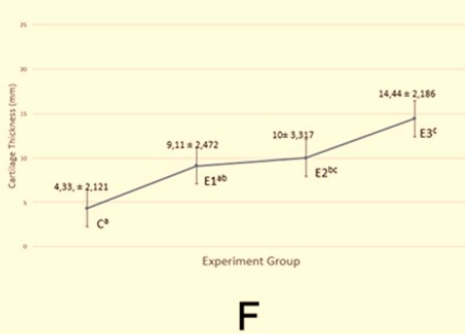

Figure 3. Microscopic image of immunohistochemical staining of cells expressing type 2 collagen (A) and aggrecan (B). Black arrows show cells expressing type II collagen and aggrecan. Examination was carried out under a light microscope at 400x magnification. HE staining of cartilage thickness (C), black arrow shows defects in the proliferative and mature zone, green arrows indicate the fibrous zone, yellow arrows indicate the mature zone, brown arrows indicate the hypertrophic zone and blue arrows indicate the subchondral bone (light microscope at 100x magnification). Graph of the mean value and deviation standard of each group, expression of type II collagen (D), aggrecan (E), cartilage thickness (F). Different superscript showed statistical differences between groups $(\mathbf{p}<0.05)$.

\section{Discussion}

The implantation of hUCMSC over PRF scaffold underwent proliferation and differentiation into chondrocytes to initiate extracellular matrix deposition. This, in turn, regenerated defective cartilage through a complex process involving various growth factors of FGF 18 and transcription factor of Sox9. In this study, the surface markers found were $\mathrm{CD} 45^{-}, \mathrm{CD}_{7} 3^{+}, \mathrm{CD} \mathrm{O}^{+}, \mathrm{CD} 105^{+}$, as previously described [14].

The proliferation of hUCMSC and chondocyte differentiation were significantly higher in the E3 group compared to other groups. This may be caused by the nature of PRF being a flexible, elastic and extremely strong fibrin matrix that fulfils the 3-dimensional requirement for biomaterial. In addition, growth factors, platelets and immune concentrate that are required in the healing and immune process were all released $[15,16]$. Seeding of hUCMSC in PRF in this study was accomplished through centrifugation where PRF had undergone polymerization that reduces thrombin concentration, thus forming tetramolecular and trimolecular bonds or extensive 3D equilateral bonds. This bonding promotes cytokin attachment, cell migration and retains stem cells within the PRF, chemotactically recruited MSC, caused by dense fibrin structure increasing growth factor and resulting in the gradual release of other mediators. This process will confine hUCMSC to the PRF [17,18]. 
The high proliferation of hUCMSC in PRF scaffold was demonstrated by the strong expression of Ki67 which results from PRF also constituting an extracellular matrix that forms tissue structure, provides regulatory signal for cell proliferation and differentiation through cell-receptor interaction, mediating diffusion of soluble growth factors and reducing mechanical signals [19]. Platelet-derived growth factor contained in PRF might induce cell proliferation through Akt signal transduction that is important in cell proliferation [20,21]. The strong expression of Ki67 was consistent with high chondrocyte counts.

High chondrocyte counts will express significant FGF 18. This study found the highest expression of FGF 18 to be in E3 group compared to the other groups in the experiment that showed no significant difference. Chondrogenic differentiation was indicated by high expression of FGF 18, that was a physiological ligand of FGFR3 [22]. Columnar and flat chondrocyte represent the most proliferative cells in cartilage expressing high FGFR3 [23] enhanced chondrogenic differentiation and cartilage production through increased expression of type 2 collagen [24]. High expression of Sox9 caused induction of chondrogenesis through Smad2/3 [25], influencing morphogenesis of the condyle [26]. Bond of Sox9 in chondocyte specific enhancer in intron 1 gen pro- $\alpha 1$ type 2 collagen upregulating the synthesis of $\alpha 1$ type 2 collagen, Sox9 maintained its high expression in fully differentiated chondrocyte [27]. This study also showed the highest expression of Sox9 to occur after 6 weeks' implantation of hUCMSC in PRF scaffold. Expression of Sox9 might be regulated by FGFR3 [28], as was indicated by the findings reported here that showed high expression of FGF 18, Sox9, and type 2 collagen, as well as aggrecan.

The collagen network in articular cartilage provides mechanical support to tensile forces generated by compression or interstitial swelling, protects chondrocyte, maintains proteoglycan attachment and attaches cartilage to subchondral bone [29]. Type 2 collagen and aggrecan were molecular markers of mature chondrocyte because they were produced by differentiated chondocytes [30]. This study confirmed a significant difference of type II collagen and aggrecan expression in hUCMSC in PRF scaffold compared to other groups consistent with the high expression of Sox9. FGF 18 released in large quantities in E3 group will upregulate Sox9 expression at several stages of chondrocyte differentiation, increase proteoglycan deposition, aggrecan and type II collagen expression and significantly decrease expression of collagen type I [31].

Regeneration of mandibular cartilage defects in hUCMSC in PRF scaffold was indicated by the highest mean of cartilage thickness. The interaction of chondrocyte and extracellular matrix regulates important processes in homeostasis and cartilage repair mediated by integrin signalling. The mechanical nature of scaffold plays an important role in tissue regeneration and at the cellular level, which affects mesenchymal stem cell differentiation [32]. The proliferation of hUMCSC and its differentiation into chondrocyte leads the latter to produce extracellular matrices such as type II collagen and aggrecan. In addition to the growth factor released by PRF, it also provides the mechanical structure required in promoting cartilage thickness. Extracellular matrices provided by PRF not only form tissue structure and function, but also provide regulatory signals for cell proliferation and differentiation through cell-receptor interaction, mediating soluble growth factor diffusion and absorbing mechanical signals [21].

\section{Conclusion}

Human umbilical cord mesenchymal stem cells in platelet rich fibrin scaffold proved capable of regenerating mandibular cartilage defect.

\section{Authors' Contributions}




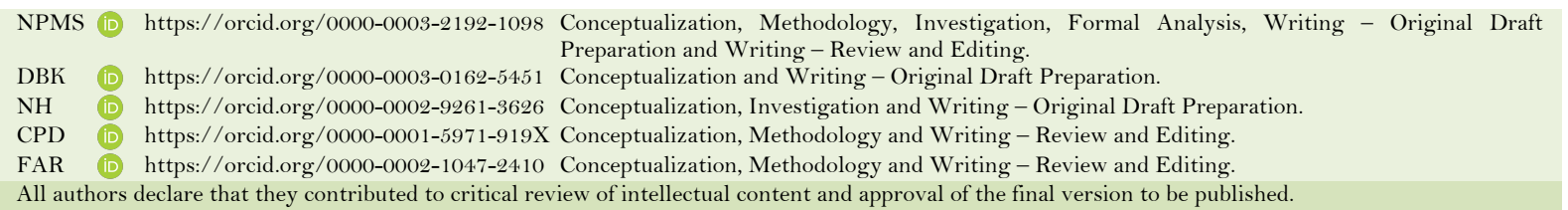

\section{Financial Support}

None.

\section{Conflict of Interest}

The authors declare no conflicts of interest.

\section{Data Availability}

The data used to support the findings of this study can be made available upon request to the corresponding author.

\section{References}

[1] Tanaka E, Detamore MS, Mercuri LG. Degenerative disorders of the temporomandibular joint: etiology, diagnosis, and treatment. J Dent Res 2008; 87(4):296-307. https://doi.org/10.1177/154405910808700406

[2] Naujoks C, Meyer U, Weismann HP, Jäsche-Meyer J, Hohoff A, Depprich R et al. Principles of cartilage tissue engineering in TMJ reconstruction. Head Face Med 2008; 4(3):1-7. https://doi.org/10.1 186/1746-160x-4-3

[3] Learreta JÁ, Yavich LG. Structural modifications of the mandibular condylar process as one of the sequels of traumatism in infancy. J Cranio-Maxillofac Dis 2014; 3(2):85-8. https://doi.org/10.4103/2278-9588.138216

[4] Goldring MB, Otero M, Plumb DA, Dragomir C, Favero M, El Hachem K, et al. Roles of inflamatory and anabolic cytokines in cartilage metabolism: signals and multiple effectors converge upon MMP-13 regulation in osteoarthritis. Eur Cell Mater 2011; 21:202-20. https://doi.org/10.22203/ecm.v021a16

[5] Punwar S, Khan WS. Mesenchymal stem cells and articular cartilage repair: clinical studies and future direction. Open Orthop J 2011; 5(Suppl 2):296-301. https://doi.org/10.2174/1874325001105010296

[6] Brittberg M, Lindahl A, Nilsson A, Ohlsson C, Isaksson O, Peterson L. Treatment of deep cartilage defects in the knee with autologous chondrocyte transplantation. N Engl J Med 1994; 331(14):889-95. https://doi.org/10.1056/nejm199410063311401

[7] Krampera M, Franchini M, Pizzolo G, Aprili G. Mesenchymal stem cells: from biology to clinical use. Blood transfus 2007; 5(3):120-9. https://doi.org/10.2450/2007.0029-07

[8] Vinatier C, Mrugala D, Jorgensen C, Guicheux J, Noël D. Cartilage engineering: a crucial combination of cells, biomaterials and biofactors. Trends Biotechnol 2009; 27(5):307-14. https://doi.org/10.1016/j.tibtech.2009.02.005

[9] Lindenmair A, Hatlapatka T, Kollwig G, Hennerbichler S, Gabriel C, Wolbank S, et al. Mesenchymal stem or stromal cells from amnion and umbilical cord tissue and their potential for clinical applications. Cells 2012; 1(4):1061-88. https://doi.org/10.3390/cells 1041061

[10] Baek HS, Lee HS, Kim BJ, Chung IK, Kim CH, Jin SM, et al. Effect of platelet-rich fibrin on repair of defect in the articular disc in rabbit temporomandibular joint by platelet-rich fibrin. Tissue Eng Reg Med 201 1; 8(6):530-5.

[11] Fortier LA, Barker JU, Strauss EJ, McCarrel TM, Cole BJ. The role of growth factors in cartilage repair. Clin Orthop Relat Res 2011; 469(10):2706-15. https://doi.org/10.1007/s11999-011-1857-3

[12] Saluja H, Dehane V, Mahindra U. Platelet-rich fibrin: a second generation platelet concentrate and a new friend of oral and maxillofacial surgery. Ann Maxillofac Surg 2011; 1(1):53-7. https://doi.org/10.4103/2231-0746.83158

[13] Kütük N, Baş B, Soylu E, Gönen ZB, Yilmaz C, Balcioğlu E, et al. Effect of platelet-rich plasma on fibrocartilage, cartilage, and bone repair in the temporomandibular joint. J Oral Maxillofac Surg 2014; 72(2):277-84. https://doi.org/10.1016/j.joms.2013.09.011

[14] Sumarta NPM, Pramono DC, Hendrianto E, Susilowati H, Karsari D, Rantam FA. Chondrogenic differentiation capacity of human umbilical cord mesenchymal stem cells with platelet rich fibrin scaffold in cartilage regeneration (in vitro study). Bali Med J 2016; 5(3):420-6. https://doi.org/10.15562/bmj.v5i3.295

[15] Hotwani K, Sharma K. Platelet rich fibrin - a novel acumen into regenerative endodontic therapy. Restor Dent Endod 2014; 39(1):1-6. https://doi.org/10.5395/rde.2014.39.1.1

[16] Choukroun J, Diss A, Simonpieri A, Girard MO, Schoeffler C, Dohan SL, et al. Platelet rich fibrina (PRF): A secondgeneration platelet concentrate. Part IV: Clinical effects on tissue healing. Oral Surg Oral Med Oral Pathol Oral Radiol Endod 2006; 101(3):E56-60. https://doi.org/10.1016/j.tripleo.2005.07.011 
[17] Dohan DM, Choukroun J, Diss A, Dohan SL, Dohan AJJ, Mouhyi J, et al. Platelet rich fibrina (PRF): A secondgeneration platelet concentrate. Part I: Technological concepts and evolution. Oral Surg Oral Med Oral Pathol Oral Radiol Endod 2006; 101(3):E37-44. https://doi.org/10.1016/j.tripleo.2005.07.008

[18] Masoudi E, Ribas J, Kaushik G, Leijten J, Khademhosseini A. Platelet-rich blood derivatives for stem cell-based tissue engineering and regeneration. Curr Stem Cell Rep 2016; 2(1):33-42. https://doi.org/10.1007/s40778-016-0034-8

[19] Dawson JI, Wahl DA, Lanham SA, Kanczler JM, Czernuszka JT, Oreffo ROC. Development of specific collagen scaffolds to support the osteogenic and chondrogenic differentiation of human bone marrow stromal cells. Biomaterials 2008; 29(21):3 105-16. https://doi.org/10.1016/j.biomaterials.2008.03.040

[20] Kim BS, Park IK, Hoshiba T, Jiang HL, Choi YJ, Akaike T, et al. Design of artificial extracellular matrices for tissue engineering. Prog Polym Sci 2011; 36(2):238-68. https://doi.org/10.1016/j.progpolymsci.2010.10.001

[21] Wu CL, Lee SS, Tsai CH, Lu KH, Zhao JH, Chang YC. Platelet-rich fibrin increases cell attachment, proliferation and collagen-related protein expression of human osteoblasts. Aust Dent J 2012; 57(2):207-12. https://doi.org/10.1111/j.1834-7819.2012.01686.x

[22] Liu Z, Xu J, Colvin JS, Ornitz DM. Coordination of chondrogenesis and osteogenesis by fibroblast growth factor 18. Genes Dev 2002; 16(7):859-69. https://doi.org/10.1101/gad.965602

[23] Zuscik MJ, Hilton MJ, Zhang X, Chen D, O’Keefe RJ. Regulation of chondrogenesis and chondrocyte differentiation by stress. J Clin Invest 2008; 118(2):429-38. https://doi.org/10.1172/jci34174

[24] Davidson D, Blanc A, Filion D, Wang H, Plut P, Pfeffer G, et al. Fibroblast growth factor (FGF) 18 signals through FGF receptor 3 to promote chondrogenesis. J Biol Chem 2005; 280(21):20509-15. https://doi.org/10.1074/jbc.m410148200

[25] Studer D, Millan C, Öztürk E, Maniura-Weber K, Zenobi-Wong M. Molecular and biophysical mechanisms regulating hypertrophic differentiation in chondrocytes and mesenchymal stem cells. Eur Cells Mater 2012; 24:11835. https://doi.org/10.22203/ecm.v024a09

[26] Su CY, Kuo YP, Tseng YH, Su CH, Burnouf T. In vitro release of growth factors from platelet- rich fibrin (PRF): a proposal to optimize the clinical applications of PRF. Oral Surg Oral Med Oral Pathol Oral Radiol Endod 2009; 108(1):56-61. https://doi.org/10.1016/j.tripleo.2009.02.004

[27] Lefebvre V, Crombrugghe B. Toward understanding SOX9 function in chondrocyte differentiation. Matrix Biol 1998; 16(9):529-40. https://doi.org/10.1016/s0945-053x(98)90065-8

[28] Murakami S, Kan M, McKeehan WL, Crombrugghe B. Up-regulation of the chondrogenic Sox9 gene by fibroblast growth factors is mediated by the mitogen-activated protein kinase pathway. Proc Natl Acad Sci U S A 2000; 97(3):1113-8. https://doi.org/10.1073/pnas.97.3.1113

[29] Chatterjee S, Jindal S. Investigation of collagen architecture in diseases of temporomandibular joint. Pathol Discov 2013; 1:7. https://doi.org/10.7243/2052-7896-1-7

[30] Shibata S, Sakamoto Y, Baba O, Qin C, Murakami G, Cho BH. An immunohistochemical study of matrix proteins in the craniofacial cartilage in the midterm human fetuses. Eur J Histochem 2013; 57(4):e39.

[31] Wang ZH, Li XL, He XJ, Wu BJ, Xu M, Chang HM, et al. Delivery of the Sox9 gene promotes chondrogenic differentiation of human umbilical cord blood-derived mesenchymal stem cells in an in vitro model. Braz J Med Biol Res 2014; 47(4):279-86. https://doi.org/10.1590/1414-431x20133539

[32] Gao Y, Liu S, Huang J, Guo W, Chen J, Zhang L, et al. The ECM-cell interaction of cartilage extracellular matrix on chondrocytes. Biomed Res Int 2014; 2014:648459. https://doi.org/10.1155/2014/648459 